\title{
ANALYSIS OF COCOA-BASED AGRICULTURAL KNOWLEDGE AND INFORMATION SYSTEMS IN THE EASTERN REGION OF GHANA
}

\author{
Codjoe F. Nana Yaw, Technical Officer \\ Bunso Cocoa College, Ghana
}

\author{
S. Asuming-Brempong, Lecturer \\ Franklin Nantui Mabe, Research Assistant \\ Department Of Agricultural Economics And Agribusiness, University Of Ghana, Ghana \\ Email: raxffrank@yahoo.com
}

\begin{abstract}
This study analyzed cocoa-based Agricultural Knowledge and Information Systems (AKIS) in Atiwa and East Akim districts of the Eastern Region of Ghana by using descriptive statistics and Total Information Score (TIS). Total Information Score (TIS) was used to rank the information sources according to the farmers' extent of contact with and usefulness of the information sources. On the whole, the total information score of mass media ranked the most frequently used and useful information sources, with personal information sources the second and public information sources third followed by private information sources ranking the least thus fourth. The study recommends for the use of mass media especially radio and television sets in availing cocoa-based information to farmers.
\end{abstract}

\section{KEY WORDS}

AKIS; Cocoa; Eastern Region; Ghana; Mass Media; TIS.

The centrality of agriculture to the development of developing economies is now beyond dispute. The role of agricultural development in Ghana for the realization of the Millennium Development Goals of the United Nations (UN, 2000) especially in the eradication of extreme poverty and hunger cannot be overemphasized. Agriculture continues to be the largest sector of Ghana's economy as its contribution to Gross Domestic Product (GDP) was 33.9 percent in 2008 and 34.5 percent in 2009. The major driving force for the growth of agricultural sector was the performance of cocoa (Institute of Social, Statistical and Economic Research, SSER, 2009).

West Africa produces 70 percent of the world's cocoa, with Côte d'Ivoire and Ghana supplying 40 and 25 percent of global consumption respectively. The average national annual yield of cocoa in Ghana is 350 kilograms per hectare $(\mathrm{kg} / \mathrm{ha})$ and this value is relatively low as compared to $800 \mathrm{~kg} / \mathrm{ha}$ in Côte d'Ivoire, and $1700 \mathrm{~kg} / \mathrm{ha}$ in Malaysia. This has been attributed to a number of factors most especially the huge knowledge gap whose consequence is low adoption of cocoa technologies by farmers (MASDAR International Consultants, 1998).

A cocoa-based AKIS is a system that links cocoa farmers (rural people) and institutions to promote mutual learning and generate, share and utilize agriculture-related technology, knowledge and information in cocoa production. The system integrates cocoa farmers, agricultural educators, researchers and extensionists to harness knowledge and information from various sources for better cocoa farming and improved livelihoods. Information and access to it are increasingly being regarded as important resources especially in the third world agriculture. Access to information is more crucial and lack of it more critical in agriculture than other areas of human endeavour International Service for National Agricultural Research; ISNAR (1991). The goal of agricultural extension service of the Ministry of Food and Agriculture (MoFA) is to facilitate farmers' acceptance of innovative practices from research which, all things being equal, leads to increase output, productivity and incomes. Central to the goal is the role of extension agents who by their functions are pivotal to the attainment of this goal. The perceptions of extension agents who are knowledge repositories that farmers look up to for information in the rural cocoa communities 
should be evaluated and incorporated into policy decisions that target increased farm productivity (Oladosu and Okunade, 2006).

Additionally, information and knowledge are regarded as essential for farmers to respond successfully to the opportunities and challenges of the physical, social and policy environments in which they operate (McQuail, 1983). It has been said that empowering the poor is about providing them with information (World Bank, 2004), and the demand for agricultural information is stronger than ever (LEISA, 2002). Knowledge gaps and information problems are key constraints to efficient functioning of markets and equitable growth and development (Garforth et al., 2003). They also influence the adoption of innovations. Boahene (1995), for example, found that the adoption of the hybrid cocoa in Ghana is influenced by lack of information concerning the existence and availability of the hybrid cocoa. Available communication strategies being used in farming communities to promote farmer learning include interpersonal exchanges, group processes (such as farmer field schools), mass media (largely radio), mixed media campaigns and in more 'sophisticated' environments, internet delivery from community telecentres (Coldevin, 2003).

Over the years, much emphasis has been on rolling out policy interventions in the form of various technologies and good agronomic practices to help cocoa farmers improve upon their production. There is however a peppercorn emphasis on the information systems and channels in the cocoa sector that would expedite these actions let alone analysis of activities, functions of the few existing information systems. This study would provide answers to the following questions:

- What are the sources through which farmers' access and exchange cocoa-based information in the selected cocoa growing areas?

- What is the extent of contact cocoa farmers have with the available information sources, and the degree of usefulness of this information?

The study of cocoa-based AKIS would serve as a an enriching storehouse for transmitting a quantity and quality of cocoa-based facts, ideas and principles with the various stakeholders, addressing the shortfall of information to enable farmers fully benefit from technology and other advances to help in the realization of the one million metric tons of cocoa output projected by Ghana Cocoa Board (Ghana COCOBOD) in 2012. Knowing the various channels and sources of cocoa-based information and technology available in the cocoa growing area will be useful to policy makers, technocrats and interventionists in designing policies in improving the access of the various sources and channels of information.

\section{STUDY AREA AND SAMPLING TECHNIQUE}

Study area. Eastern Region is an important cocoa production area of Ghana because it was the first point of introduction of the crop in 1879 (Okali, 1983; Hill, 1963). The selected districts for this study are Atiwa and East Akim. Out of 17 districts in the region, Atiwa and East Akim districts produce the largest amount of cocoa.

The Atiwa district is located in the north-western part of the region. It shares boundary with the Kwahu west municipal to the north, East Akim municipal to the south, Birim central municipal to the west, Fanteakwa to the east and south-west. The inhabitants are predominantly farmers cultivating cocoa, oil palm, plantain, cassava, yams and various vegetables, but cocoa and oil palm are the main cash crops. All these crops do well because rainfall $(1,800 \mathrm{~mm}$ per annum) influenced by the Atiwa mountain range is well distributed throughout the year.

The East Akim is located at the central portion of the Eastern Region with a total land area of approximately $725 \mathrm{~km}^{2}$. The inhabitants are mainly farmers with cocoa and oil palm being the main money earners. However, food production is very prominent especially by large settler population of Krobos and Ewes. 


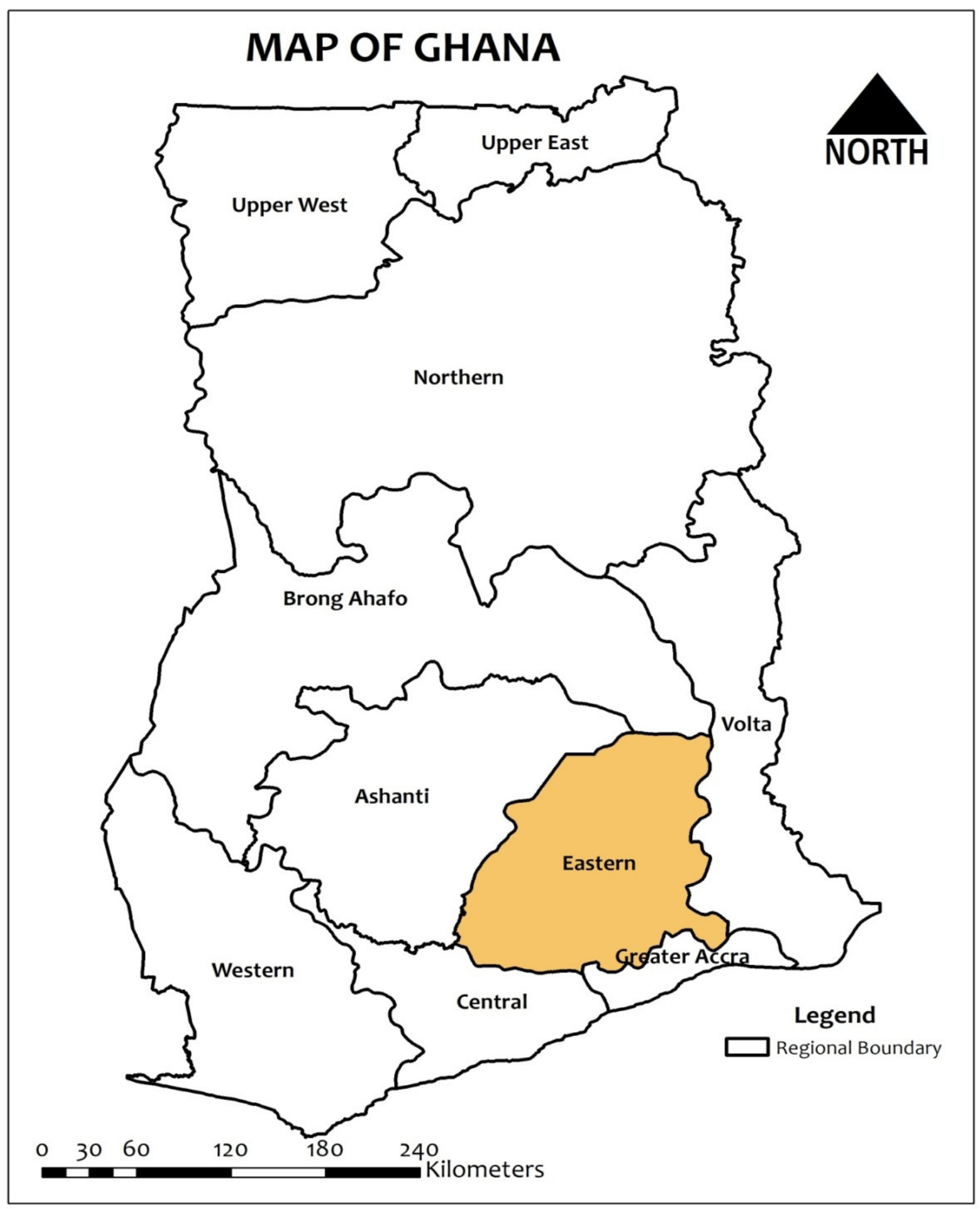

Figure 1. Map of Ghana Showing Eastern Region

Source: Survey information, 2010-2011 


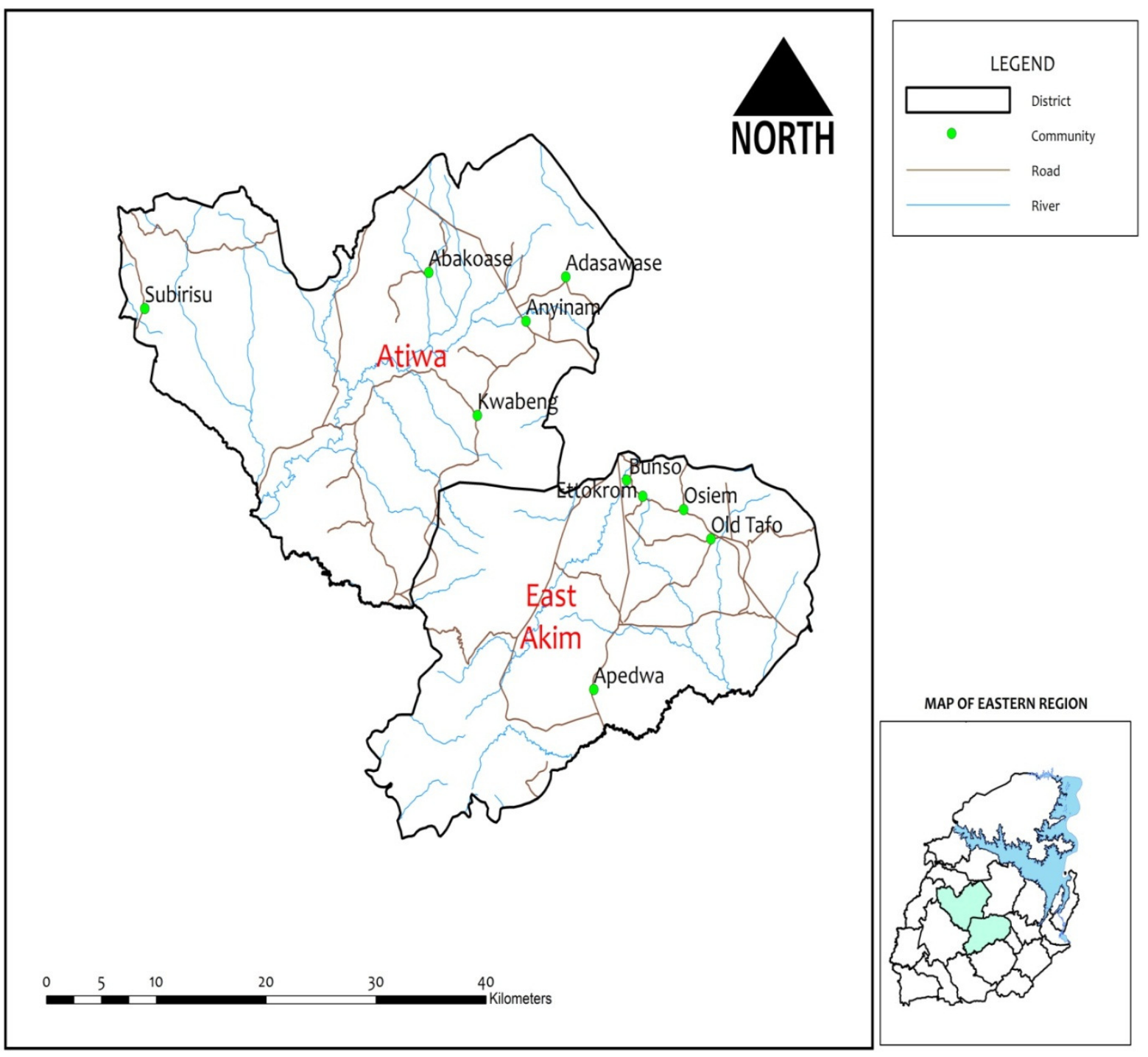

Figure 2. Map of Atiwa and East Akim Districts Showing Selected Cocoa Growing Communities

Source: Survey information, 2010-2011

Sampling technique. Primary data for the study were collected through the administration of structured questionnaires as well as interviewing sample of farmers and key informants in the study area. The secondary sources were published books, journals and reports. Eastern Region was selected purposively as the study area because extension agents as well as the farmers are relatively more accessible by the researcher. The two districts, Atiwa and East Akim were selected randomly by writing on pieces of paper the names of all the districts, mixing it in a bowl and picking one without replacement. Within the districts, the list of operational communities of the Produce Buying Company (PBC) was used as a sampling frame. Five communities were selected randomly in each district. PBC is the leading cocoa buying company with presence in all the communities and has shown in the past to have reliable records of farmers in their communities. A sample size of 300 farmers was selected across the ten communities, 150 from each district. The communities were selected using the systematic sampling technique where every $5^{\text {th }}$ farmer was selected from the list of farmers provided by the PBC. The selected communities in Atiwa district include Anyinam, Abakoase, Kwabeng, Adasawase, and Subrisu. In the East Akim districts, communities selected were Old Tafo, Osiem, Bunso, Apedwa and Ettokrom. The data were collected in two stages. Firstly, farmers were asked to list the sources and channels through which they get cocoa-based information and technology. In the second stage, the identify 
information channels were presented to the farmers to indicate the frequency of receiving information from a particular channel and the usefulness of the information in cocoa production.

\section{METHODOLOGY}

Conceptual Framework. A conceptual framework has been described as a formal way of thinking (i.e. conceptualizing) about a process or a system under study (Smith, 2004). The concept of AKIS was coined by Röling (1986). According to FAO and World Bank (2000), "an AKIS links people and institutions to promote mutual learning and generate, share and utilize agriculture-related technology, knowledge and information. The system integrates farmers, agricultural educators, researchers and extensionists to harness knowledge and information from various sources for better farming and improved livelihoods."

Technology refers to the combination of knowledge, inputs and management practices which are used together with productive resources to gain a desired output. Transfer of technology is not merely the means of transferring knowledge, information and skills about technology to its potential users but also a way of helping them to use these technologies fruitfully to their advantages. This study used the conceptual framework shown in figure 3 below.

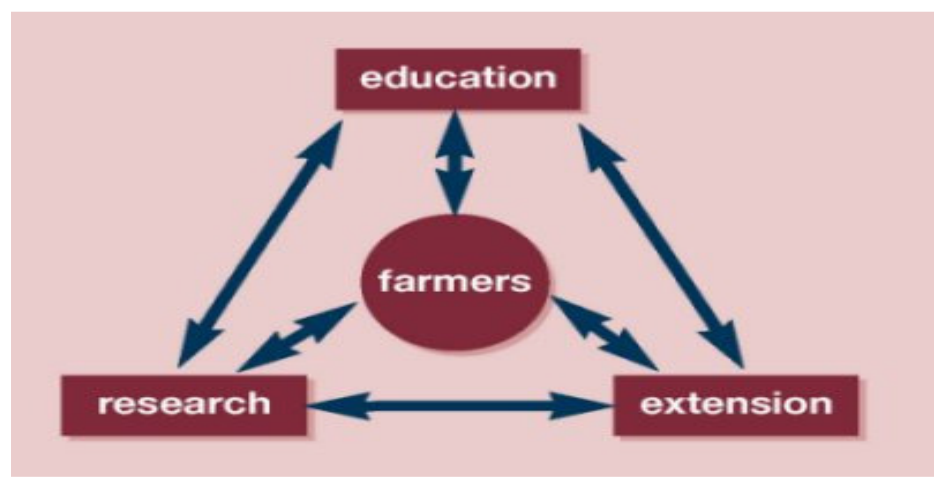

Figure 3. An overview of the conceptual framework of AKIS

Source: FAO and Word Bank (2000)

\section{Method of data analysis.}

Sources of cocoa-based information and technology exchange. Farmers' access to and use of information sources was explored through participatory information mapping. With this, questionnaires were used to interview farmers on the sources from which they obtain information about cocoa farming. Descriptive statistics in form of frequencies and percentages were used to describe the distribution of the identified information sources and technology exchange.

Extent of farmers' contact with information sources and their usefulness. In order to define the last two concepts, the respondents were asked to specify the various channels of information with their frequency of contact (both receiving and giving information) for the previous year. The channel of information and technology exchange in this study is the means through which farmers receive from or give information to the main sources (personal information sources, public information sources, private information sources and mass media). Therefore, under each of these information and technology sources are many information channels. The identified channels were group under personal information sources, public information sources, private information sources and mass media. In addition, they were asked to score the degree of usefulness of these channels. The score values for the frequency of contact and the weighted values of the usefulness of the information sources were used to calculate the total information score.

Calculation of information scores. According to Demiryurek (2000), information scores for each component of the farmers' agricultural information system can be calculated 
by multiplying the weights of information contact with degree of information usefulness. Following Demiryurek (2000), Total Information Score (TIS) is formulated as:

$$
T I S_{i j}=\sum_{i}^{j} F C_{i j} * I U_{i j}(1)
$$

where $\mathrm{FC}_{\mathrm{ij}}$ is the number of contact with $\mathrm{j}$-th information channel to the $\mathrm{i}$-th cocoa farmer and $\mathrm{IU}_{\mathrm{ij}}$ is the usefulness of $\mathrm{j}$-th information channel to the $\mathrm{i}$-th cocoa farmer.

The weights were given to each component according to the extent of information contact. The weight of 0 was given to no contact, 1 for once a year, 2 for two or three times a year, 4 for four or five times a year, 12 for once a month, 30 for two or three times a month, 52 for once a week, 130 for two or three times a week and 365 for information contacts once a day. Similarly, the degree of usefulness of information sources was also weighted. The weight of 0 was given to not useful at all, 0.25 for little useful, 0.50 for somewhat useful, 0.75 for useful and 1.00 for very useful. The scores were calculated on the basis of percentages of farmers' reporting each level of use of the sources.

\section{RESULTS AND DISCUSSION}

Socio-economic characteristics of respondents. Due to the fact that older people generally stay in the villages and relatively younger people go to cities for education, learning of trade and in search of white-colour jobs, majority (57.0\%) of the farmers are in the older age bracket thus, 56 and above. Cocoa farming in the study area appears to be male dominated, with $68.0 \%$ of the respondents being men. This may be attributed to the exertion of physical energy required in cocoa cultivation.

The greatest percentage $(38.3 \%)$ of the respondents had primary education, while $2.3 \%$ which represents the smallest percentage had adult literacy education. By implication, it is somewhat certain that these prevailing educational levels could affect farmers' knowledge and the way they look at new technologies because a bulk of them had just basic education. Majority (32.0\%) of the farmers have been in cocoa farming for just 1-10 years. This indicates that cocoa farming in the study area are dominated by new entrants and hence require a lot of information and knowledge in cocoa production. From table 1, the number of farmers engaged in cocoa production decreases with experience. Out of 300 respondents, $94.0 \%$ of them had a farm size of 1.5 acres and above while $6.0 \%$ cultivated 1.5 acres of fertile land and below. With regards to the marital status of farmers in the selected cocoa growing communities, majority (69.0\%) of the respondents are married, 2.3 percent and 17.0 percent are singled and widowed respectively.

Furthermore, about $40.7 \%$ have family land ownership whereas a total of $52.0 \%$ of the farmers own land through outright purchase, gift and rent. Additionally, $73.0 \%$ of the respondents farms are in the farm age range of 1-20 years indicating the presence and dominance of young cocoa ( $\mathrm{A}$ and $\mathrm{B}$ class) farms in the study area. Table 1 also reveals that, $95.3 \%$ of the farmers in the study area fund their own farming activities while $3.0 \%$ and $1.7 \%$ source funds from cooperatives and money lenders respectively. As a result of this, farmers are still cultivating on smaller scales. Finally, farmers in the study area expressed varied reasons why they are involved in cocoa cultivation. Majority $(52 \%)$ of the farmers cultivate cocoa in order to generate revenue to meet their financial needs while $46.0 \%, 0.3 \%$ and $1.0 \%$ cultivate cocoa for asset accumulation, social prestige and other reasons respectively. This depicts the varied levels of seriousness in terms of how farmers treat and see farming either as a business or just a source of living.

Sources of cocoa-based information and technology exchange. The identified widely used information sources by farmers were categorized into four according to their similarities, namely: personal information sources, public information sources, private information sources and mass media. The components or details of these sources are termed channels through which information and technology are transferred.

Table 1 shows the distribution of the main sources of information and knowledge access and exchange by farmers in the study area. About $54.3 \%$ of the farmers get their 
information from personal sources, followed by the mass media, public and private sources with percentages of $26.0 \%, 18.3 \%$ and $1.3 \%$ respectively. This explains that, at the village level, farmers source information and knowledge on cocoa mostly from their colleague farmers, family members (personal sources) as well as from their small radios and television (mass media) more often than from extension agents, research institutes and university staff (public); not glossing over input dealers and (LBC's) Licensed Buying Company's (private). This findings confirms the assertion by McQuail (1983), that the mass media, including radio, newspapers, television, video/film, audiocassettes and theater/drama, hold much appeal and have played and continue to play increasingly important role in extension and social development work. Expatiating on this findings, it implies that even though the private and especially the public sources are present in the study area, due to logistical and varied constraints, their frequency of contact with farmers is minimal, hence farmers sought for information mostly from the personal and mass media sources.

Table 1. Distribution of sources of cocoa based information and technology exchange

\begin{tabular}{|c|c|c|}
\hline Source of cocoa based information & Frequency & Percentage \\
\hline Personal & 163 & 54.3 \\
\hline Private & 4 & 1.3 \\
\hline Public & 55 & 18.3 \\
\hline Mass Media & 78 & 26.0 \\
\hline Total & 300 & 100 \\
\hline
\end{tabular}

Source: Compiled from survey data, 2010-2011.

Extent of contact and usefulness of cocoa-based information sources. Table 2 shows that, cocoa farmers in the study area undoubtedly used a wide range of information channels under each of the major information sources. Although most channels were common to the cocoa farmers, two of these were implicitly exclusive, namely the personal computers/internet and telecommunication networks which were ranked least. Despite the influx of telecommunications networks in the country, none of them currently has developed an extension delivery package for farmers regarding their agronomic practices.

The rankings of the personal information sources show that family members ranked third as the most valued information source in that category followed by other farmers/farmer association ranking fourth. By implication, cocoa farmers in the study area prefer giving out and receiving cocoa-based information mainly through their family members who are one way or the other directly and indirectly engaged in cocoa cultivation or activities. Most of the farmers also find it useful and beneficial to contact other farmers and village extension animators for cocoa-based information and technology. The limitation in this case is that, information exchanged through these means may be outmoded and irrelevant due to changing situations such as climate change, soil fertility and other related factors. This suggests that activities of farmer association/other farmers as well as family members should be evaluated more frequently to update members on current agronomic practices and technologies to eschew the use of outmoded information. Furthermore, it indicates the presence of farmer groups in the study area hence the need to encourage more farmers to get involved in such organization as it will make extension work easier.

The private information sources subsystem consisted of association experts, licensed buying companies (LBC's), cocoa farm input dealers and telecommunication networks. The Licensed Buying Companies (LBC's) and the cocoa farm input dealers were widely used by farmers in this category, which may indicate that they were perceived as credible sources of information on cocoa cultivation. The private information sources and specifically the telecommunication networks did not function much as information sources for cocoa farmers thereby ranking last thus fourth.

The association experts are the key people in the system and have two main responsibilities, namely the management of organizational activities (office work) and the services of technical and information supports (fieldwork). Although the association experts were one of the main sources of information for cocoa farmers, they were not more important 
than family members and other farmers/farmer association members. This situation compelled cocoa farmers to employ more Personal information sources and to generate and exchange their own information sources and this is evident, by it ranking the second most important and widely used source of information.

The public information sources were information sources from outside the villages and operated by professional staff of various institutions. Although they were supposed to be the main scientific and technical support services for the cocoa farmers, they were rarely used. The information exchanges between the cocoa farmers and the public information sources were generally weak and limited. The main reasons for this were inadequate extension agents and logistic constraints. From these findings, it could be concluded that cocoa farmers are being treated unfairly in terms of provision of extension services to them. According to Baah (2002), Ghanaian cocoa farmers already pay for extension services through the taxes deducted by government on the cocoa beans bought. Government must therefore ensure adequate and timely release of funds for cocoa extension. Moreover, this study supports the works of several other authors such (Ameur, 1994; Umali and Schwartz, 1994; Rivera, 1996) who have advocated for the involvement of the private sector in extension provision to farmers, criticizing the public sector institutions for being largely out of touch with the needs of the clients.

The most important and frequently used source of cocoa-based information and technology in the study area is mass media. Cocoa farmers somewhat benefited more from some media information channels thus radio programmes, television programmes and the agricultural manuals as these are supported by the ranks of first, second, seventh and tenth position respectively. On the whole, the total information score of mass media ranked the highest (1), with personal information sources the second and public information sources third followed by private information sources ranking the least thus fourth.

Table 2. Scores and rank orders of information sources

\begin{tabular}{|l|l|l|}
\hline & \\
\hline & & \\
\hline
\end{tabular}

Source: compiled from survey data, 2010-2011.

\section{POLICY RECOMMENDATIONS}

This research has revealed that for cocoa-based AKIS to be strengthened to be uniquely positioned to perform it task, collective effort by all actors along the AKIS chain is crucial. This should be manifested through the countless engagements in form of fora, 
meetings and seminars to update themselves in their quest for information dissemination. Farmers who happen to be direct beneficiaries of this chain are however looking forward to frequent interactions with their extension agents, researchers, as well as making available regular and relevant training programmes for them. This would go and long way to strengthen farmer to farmer interactions.

There is a wide scope for ICTs for effective extension outreach, a particularly valuable tool in isolated areas. It is recommended that telecommunication networks should be encouraged to set up community telecentres to offer internet delivery to farmers or establish a helpline where farmers could call to access information concerning their farm activities in their own local languages. Such technological and institutional packages if optimally tailored to peasants' economic behaviour will greatly enhance the chances of success of rural development interventions and programmes. Additionally, efforts should be made to scale-up the cocoa-link project (where mobile phones are used to send message to farmers on farm operations) from its present pilot phase to cover more geographical areas. The scaling-up should also be institutional, bringing in more stakeholders (such as the NGOs, and the telecommunication networks) to enhance the sustainability of the incorporation of the approach into the cocoa extension set-up.

The attitude of ugly politicization of distribution of farm inputs and government programs such as the cocoa mass spraying exercise should be strongly abhorred to allow the even distribution of this national cake for the benefit of all. Furthermore, as a measure to overcome this technological constraint it is again recommended that the Ghana Cocoa Board should give inputs directly to farmers who sell their dried cocoa beans to LBC's recognized by Ghana Cocoa Board or to farmers who are in registered and recognized farmer groups or associations. It is also recommended that PPP (Private Public Partnership) in cocoa extension be strengthened to ensure an effective extension delivery.

\section{CONCLUSION}

The study analyzed cocoa-based Agricultural Knowledge and Information Systems (AKIS) in two selected cocoa growing districts (Atiwa and East Akim) in the Eastern Region of Ghana.

The research found out that at the village level, farmers sought for information and knowledge on cocoa mostly from their colleague farmers, family members (personal sources) as well as from their small radios and television (mass media) more often than from extension agents, research institutes and university staff (public). Thus personal source was the predominant source through which farmers' access and exchange cocoa-based information in the study area. On the whole, the Total Information Score of Mass media ranked the highest (1), with Personal information sources (2) and Public Information sources (3) followed by Private Information sources ranking the least (4). By implication, the most frequently used as well as the most useful cocoa-based information is obtained from media (i.e., radio programmes, television programmes and the agricultural manuals).

It is therefore recommended that deliberate policy should be put in place to guarantee easier and affordable access to cocoa-based AKIS. Farmers should be given television and radio sets to enable them get access to media information on cocoa. Policies should be put in place for Agricultural Extension Agents to education farmers on cocoa production technologies through national and private television and radio stations in the country.

\section{REFERENCES}

[1] Ameur, C. (1994). Agricultural Extension: A step beyond the next step. World Bank Technical Paper No. 247, World Bank, Washington D.C, pp.10-25.

[2] Baah, F. (2002). Cocoa Cultivation in Ghana: An analysis of Farmers Knowledge and Information Systems and attitudes. PhD Thesis, Institute of International Development and Applied Economics, University of Reading, UK, P.292. 
[3] Boahene, K. (1995). Innovation adoption as socio-economic process: The case of the Ghanaian cocoa industry, Thesis Publishers, Amsterdam.

[4] Coldevin, G. (2003) Participatory communication: Key to rural learning systems, Food and Agricultural Organization, Rome.

[5] Demiryurek, K. (2000). The analysis of information systems for organic and conventional hazelnut producers in three villages of the Black Sea Region, Turkey. Unpublished doctoral dissertation, University of Reading, Reading, UK.

[6] FAO and World Bank. (2000). Agricultural Knowledge and Information Systems for Rural Development (AKIS/RD): Strategic Vision and Guiding Principles, Food and Agriculture Organization of the United Nations, and World Bank Rome.

[7] Garforth, C., Khatiwada, Y. and Campbell, D. (2003). Communication research to support knowledge interventions in agricultural development: Case studies from Eritrea and Uganda, Paper presented at the Development Studies Association Conference, Glasgow, 10-12 September 2003.

[8] Ghana Cocoa Board (2008). Cocoa Production Statistics 2006, Accra Research Department, Ghana Cocoa Board (COCOBOD).

[9] Hill, P. (1963). The Migrant Cocoa Farmers of Southern Ghana: A study in Rural Capitalism. Cambridge: Cambridge University Press.

[10] ISNAR (1991). Review of Ghana Agricultural Research System, Vol. 11, Annexes, International Service for National Agricultural Research (ISNAR), The Hague.

[11] ISSER (2009). The State of the Ghanaian Economy, Institute of Statistical, Social and Economic Research, University of Ghana, Legon.

[12] LEISA (2002). Changing information flows: Editorial introduction. Leisa 18 (2) 4-5.

[13] MASDAR International Consultants (1998). Socio-economic Study of Cocoa Farming in Ghana. Consultancy Report, Accra: Ghana Cocoa Board / MASDAR International Consultants.

[14] McQuail, D. (1983.) Mass communication theory. London: Sage publications.

[15] Okali, C. (1983). Cocoa and Kinship in Ghana: The Matrilineal Akan of Ghana, Kegan Paul International, Boston.

[16] Oladosu, E.O. and Okunade E.O. (2006). Perception of village extension agents in disseminating agricultural information in Oyo Agricultural Zone of Oyo State, Nigeria. J. Soc. Sci. 12(3): 187-191.

[17] Rivera, W.M. (1996) 'Agricultural extension in transition worldwide: structural, financial and managerial strategies for improving agricultural extension' Public Administration and Development, vol. 16, pp. 151-61.

[18] Röling, N. (1986). Extension science: increasingly preoccupied with knowledge systems. Sociologia Ruralis, 25: 269-290.

[19] Smyth, R. (2004). Exploring the usefulness of a conceptual framework as a research tool: a researcher's reflections of Issues in educational research, 14, Online: http;//education.curtin.edu.au/iier/iier14/smyth.html, [accessed: 20/02/2010].

[20] Tiwari, T.P., Brook, R.M. and Sinclair, F.L. (2004). Implications of hill farmers'agronomic practices in Nepal for crop improvement in maize. Exp. Agric. 40:397-417.

[21] Umali, D.L. and Schwartz, L. (1994). Public and private agricultural extension: Beyond traditional frontiers. Washington, D.C.: The World Bank.

[22] UN (2000). Millennium Development Goals www.un.org/millenniumgoals/bkgd.shtml, Accessed 24/10/2010. 